
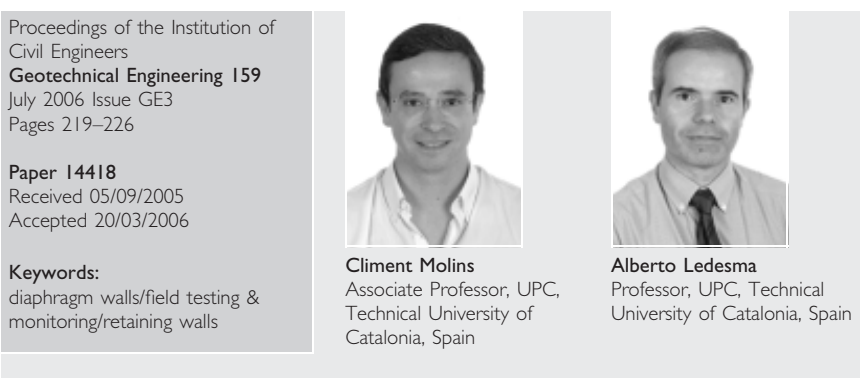

\title{
Building a deep isolating wall by an existing rail tunnel
}

\author{
C. Molins PhD and A. Ledesma PhD
}

This paper describes the design, construction and early performance of a retaining structure close to a subway tunnel in Barcelona. The excavation, about $16 \mathrm{~m}$ deep, was carried out in $\mathbf{2 0 0} \mathrm{I}$ during the construction of a new hospital, and involved a rectangular area with the longer side $(170 \mathrm{~m})$ almost parallel to the tunnel. The design had to fulfil two requirements: first, the influence of the excavation on the existing tunnel had to be minimised; and, second, the new hospital had to be isolated from vibrations from the subway owing to the high sensitivity of the medical instruments. In order to achieve this, the retaining wall was designed to be independent of the main building, and movements during the excavation stages had to be controlled. In addition, the use of subhorizontal anchors was not allowed by the metro administration, and therefore the wall comprised a line of T-shaped panels linked to shorter intermediate panels excavated using a hydromill. The stability of the wall and bending resistance were provided by the buttressing effect of the forward-facing $T$ and the compression in the panels and anchoring force provided by post-tensioning anchors drilled into the underlying bedrock through ducts installed in the rear section of the $T$ panels. The wall was designed using a beam-spring model with ground parameters derived from in situ tests, and the interaction between the excavation and the tunnel was modelled using a plane-strain finite element analysis imposing the wall displacements on the section.

Monitoring of the wall and the tunnel confirmed that the influence of the work on the neighbouring tunnel was negligible.

\section{INTRODUCTION}

The diaphragm wall presented in this paper was built in Barcelona in 2001 to retain a vertical cut of 14-16 m between the upper street and the base of the future buildings of the new Hospital de la Santa Creu i Sant Pau. An existing subway tunnel under the upper street was close to the excavation area and had an important influence on the design and construction of the Hospital. The tunnel was only $3.5 \mathrm{~m}$ away from the designed wall at its nearest point. It was $7.50 \mathrm{~m}$ wide and was bored about 50 years ago. Its plain concrete lining was approximately $1.00 \mathrm{~m}$ thick in the side walls and $0.50 \mathrm{~m}$ at the crown. The interaction between the new buildings and the existing tunnel was critical in this case. On the one hand, the metro administration asked for a minimum influence of the excavation on the existing tunnel in order to prevent severe cracking or joint opening in the plain concrete lining. On the other hand, vibrations caused by the subway trains should not reach the main building, because of the high sensitivity of the medical instruments in the surgical area that would be placed in the basement. In fact this latter condition made it necessary to design the whole building in terms of a base-insulation system.

Initially, the diaphragm wall was designed to stand alone with ground anchors without connection to the new building, in order to cut off vibrations. However, the metro administration did not allow the construction of permanent anchors under their tunnels, and therefore a self-retaining structure was considered. A diaphragm wall $100 \mathrm{~m}$ long, buttressed and vertically prestressed, was designed in order to minimise the common interactions between the main building and the existing tunnel. Additionally, the retaining structure was separated from the main building by means of a $50 \mathrm{~mm}$ joint. In fact, the joint was $4.40 \mathrm{~m}$ away from the intrados, parallel to the wall, and the portion of slabs between buttresses was supported both by them and by the diaphragm wall.

The influence of the retaining structure on the existing tunnel was basically defined in terms of induced displacements. Thus, in order to predict those movements, a comprehensive geotechnical characterisation of the site was carried out. Different techniques were considered, including standard laboratory experiments and horizontal loading plate tests in a small existing adit. They are described in the next section.

Additionally, prestressing was used (a) to prevent cracking of the concrete of the wall and (b) to stabilise the whole retaining system with its vertical and eccentric force, anchored in the bedrock. Post-tensioned diaphragm walls were pioneered by I $\cos ^{1} 30$ years ago to reduce the amount of vertical reinforcement within the wall. However, there are few examples of post-tensioned diaphragm walls, some of them designed by Gysi, ${ }^{2,3}$ because of the difficulties found in achieving the required accuracy during construction: fixing the ducts for eccentric cables, placing the cage in position, and concreting the wall. In addition, unless the wall is very high, a large number of short tendons are usually required. As is well known, a short length of the tendons implies, first, high loss of stressing force due to wedge penetration and, second, a significant cost impact of anchoring devices and operations. 
Anchors in geotechnical engineering are usually not bonded to the concrete structure. In this case, bonding after posttensioning provided a better performance of the wall as a prestressed structure subjected to considerable bending, and protected its whole length against corrosion. The anchors were designed to prevent corrosion using conventional techniques (i.e. corrugated ducts made of an impervious high-resistance material), and control of load and displacements was performed in all of them.

The gap left between the wall and the hospital was considered large enough to prevent contact between both structures. Some aspects that were taken into account were

(a) the lack of a high water table

(b) the drainage of the area that was performed when building the wall, collecting small local water flows in rock joints

(c) the existence of two extra ducts in the primary panels that could be used in the future if necessary.

Visual checking and measurement of this gap may be performed regularly, as it is fully visible.

The wall and the wall-tunnel interaction were designed using finite elements. In some structural analyses the Winkler approach was adopted to simulate the soil-structure interaction. Some sensitivity analyses of the wall displacements with respect to the embedded length were carried out as well. They are briefly described in Section 3. Finally, the paper describes in Sections 4 and 5 some relevant aspects of the construction stages and the monitoring of the wall displacements.

\section{GEOTECHNICAL SITE INVESTIGATION}

A typical cross-section of the site is depicted in Fig. 1. The section corresponds to the zone where the tunnel is close to the construction site. The soil profile consists of $1 \mathrm{~m}$ of fill, 5-8 m of Barcelona stiff clay and a shale baserock. The location of boreholes 3 and 4 is also indicated in the figure.

The stiff clay is a quaternary soil, common in the city, derived from erosion of the coastal range mountains. It is slightly overconsolidated owing to past episodes of drought, water table changes and carbonation, with $60 \%$ passing the No. 200 sieve, a liquid limit of 32 and plastic limit of 16 . According to the Unified Soil Classification System, it can be classified as low-plasticity clay (CL).

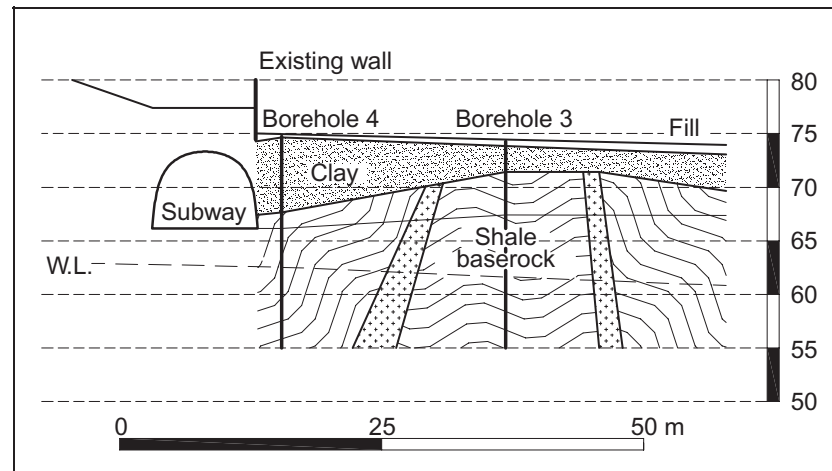

Fig. I. Geological profile
The shale is a Palaeozoic rock intruded by some dykes of granite rocks. The shale close to the clay contact is weathered and presents many fissures, with a rock quality designation (RQD) index of almost nil. Its quality improves with increasing depth, from a soil-like material to a rock with an unconfined strength of $28 \mathrm{MPa}$. Because of this, two different layers were distinguished within the shale, the weathered one having an estimated thickness of $2 \mathrm{~m}$.

The geotechnical investigation involved several activities, including boreholes to define the geological profile and to take out undisturbed samples for laboratory testing. Standard penetration tests were performed when possible. In addition to this, some field tests were planned in order to check the properties of the baserock. Note that an important part of the retaining wall should be in contact with this material and, because of this, several anchor/micropile tests and plate load tests were also carried out. Failure analysis of the anchors and micropiles gave a limiting value of $380 \mathrm{kPa}$ for the shear strength of the contact between baserock and concrete, showing an almost elastic response before failure.

Plate load tests were performed on vertical cuts, in order to estimate the Winkler coefficient of the soil. This parameter is of common use in many structural analyses because of its simplicity, despite the difficulties in defining a specific value for each geometry and soil. In this case it was considered that horizontal load tests were suitable for such estimation. Three tests were performed: two over the walls of ditches dug specifically from the top of the construction site (that is, involving clayey soil), and a third one on the walls of a small existing adit that carried water for drainage purposes. That small tunnel was in altered shale, which made it possible to obtain information on that material in this field experiment. A simplified layout of the test is shown in Fig. 2.

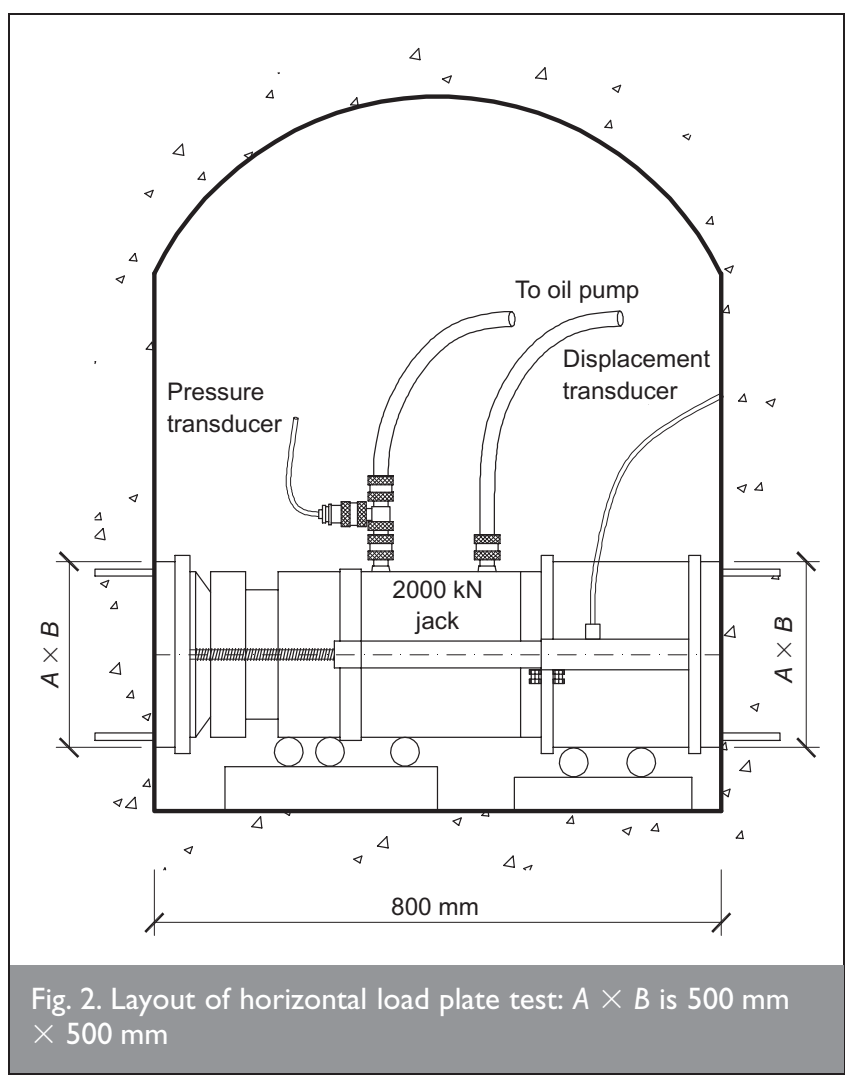


Table 1 presents a summary of the basic design parameters adopted. They were decided upon taking into account both the available laboratory and field tests available and local experience from the area. Regarding the clayey material, the laboratory values were preferred, because the plate tests performed well above the water table and yielded high strength values owing to the unsaturated conditions of the soil. With respect to the rock, it was more difficult to estimate appropriate strength parameters, because the available data were very limited. It was known that some joints of the shale may exhibit low strength properties, although the field survey did not identify any large plane capable of slipping. Finally it was assumed that strength was dependent more on the cohesion parameter than on friction for the intact rock. For the friction, a conservative value similar that measured for clay was considered. Regarding the altered shale, a predominantly frictional behaviour was assumed, and the results from the horizontal plate test in shale were very useful for this determination.

Interpretation of the plate load tests is not straightforward, particularly when the Winkler coefficient is required. The ultimate state was analysed by means of the bearing capacity expressions, and this provided information on the strength properties. By contrast, the elastic properties and therefore the subgrade reaction coefficient were obtained directly from the force-displacement curve. However, the dependence of that coefficient on the geometry is well known, and a value for design purposes was estimated taking into account some published suggestions regarding size effect. ${ }^{4-6}$ Because of the difficulties in defining this coefficient, a range of values rather than a fixed one was considered in the stability and deformability calculations described in the next section.

Elastic soil and rock properties (Young's modulus and Poisson's ratio) were used in the analyses of the interactions between retaining wall and tunnel. Because of the geometry, it was mainly the clay and the altered shale layers that were involved in this interaction, and therefore a distinction was not made between shale and altered shale. Poisson's ratios were fixed assuming reasonable values.

In general, drained conditions were assumed in all geotechnical analyses, basically because most of the materials involved were unsaturated. The water table level indicated in Fig. 1 corresponds to the highest level found during several months prior to the construction work.

\section{DESIGN}

The design consisted of a diaphragm wall $0.65 \mathrm{~m}$ thick with buttresses also $0.65 \mathrm{~m}$ thick and spaced $7 \cdot 20 \mathrm{~m}$ apart, which form a tapered T-shape cross-section. ${ }^{7}$ Fig. 3 presents a front view and a plan of the central area of the wall (buttresses 7 to 11), where the tunnel is closer to the site. The geological profile depicted in Fig. 1 corresponds to a section around buttress B10.

Figure 4 shows a typical profile of the buttress, including the wall geometry and the tunnel. A detailed plan is presented in Fig. 5. The flange of the T section is $5.00 \mathrm{~m}$ wide and forms the primary panels, which are $17 \cdot 70 \mathrm{~m}$ high. The prestressing force was provided by five post-tensioned tendons of nine strands 0.6 inches $(1.5 \mathrm{~mm})$ in diameter with Y1860S7 steel, of 1860 $\mathrm{N} / \mathrm{mm}^{2}$ of strength, placed in the flange of the T section. A total of seven ducts were installed in the panels but only five were actually used; the remaining two were left in case of unexpected problems when drilling the bedrock.

Secondary panels, in between the primary ones, are $2 \cdot 20 \mathrm{~m}$ wide and only $9 \cdot 80 \mathrm{~m}$ high (Fig. 3). These transmit earth pressures to the primary panels by means of horizontal bending and shear. Thus each primary panel and the corresponding buttress constitute the T section responsible for the stability of the wall. Below level $67.02 \mathrm{~m}$ the embedded ground between the buttresses was left to constitute a berm, contributing to the global stability.

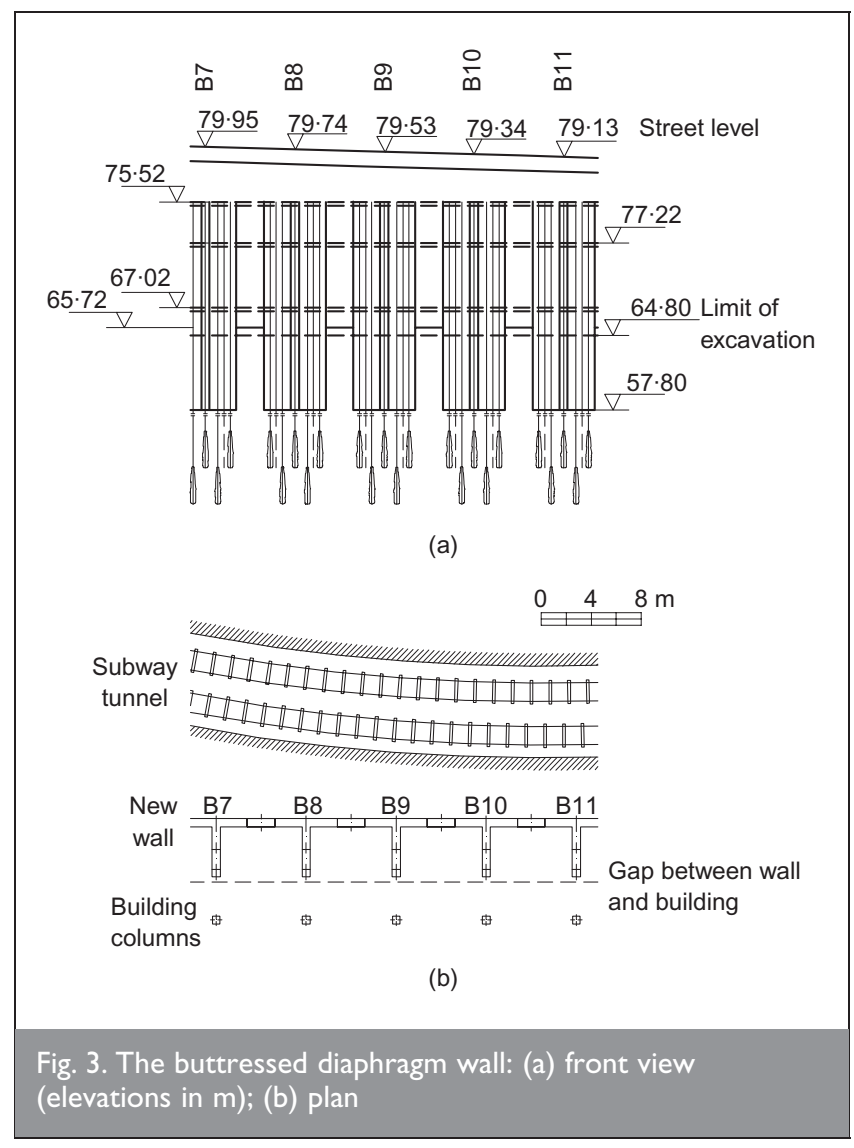

\begin{tabular}{|lcccccc}
\hline Material & $\begin{array}{c}\text { Specific weight, } \\
\gamma: \mathrm{kN} / \mathrm{m}^{3}\end{array}$ & $\begin{array}{c}\text { Cohesion, } \\
\mathrm{c}^{\prime}: \mathrm{kN} / \mathrm{m}^{2}\end{array}$ & $\begin{array}{c}\text { Friction angle, } \\
\phi: \text { degrees }\end{array}$ & $\begin{array}{c}\text { Elastic modulus: } \\
\mathrm{MPa}\end{array}$ & $\begin{array}{c}\text { Poisson's ratio } \\
\text { Winkler coefficient, } \\
\mathrm{K}_{\mathrm{b}}: \mathrm{MN} / \mathrm{m}^{3}\end{array}$ \\
\hline Barcelona Clay & 20 & 15 & 28 & 250 & $0 \cdot 3$ & 150 \\
Altered shale & 21 & 50 & 35 & 500 & $0 \cdot 2$ & $250-380$ \\
Shale & 21 & 200 & 28 & 500 & $0 \cdot 2$ & $380-500$ \\
& & & & & \\
\hline
\end{tabular}




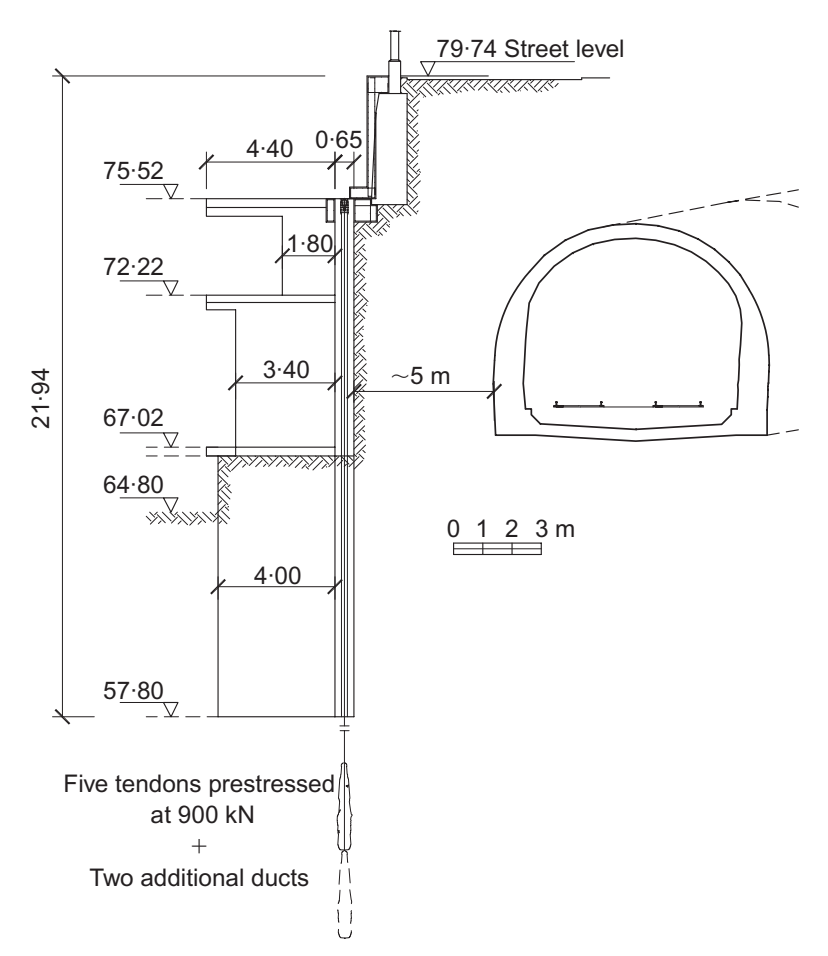

Fig. 4. Profile of wall and buttress (profile around buttress B8)

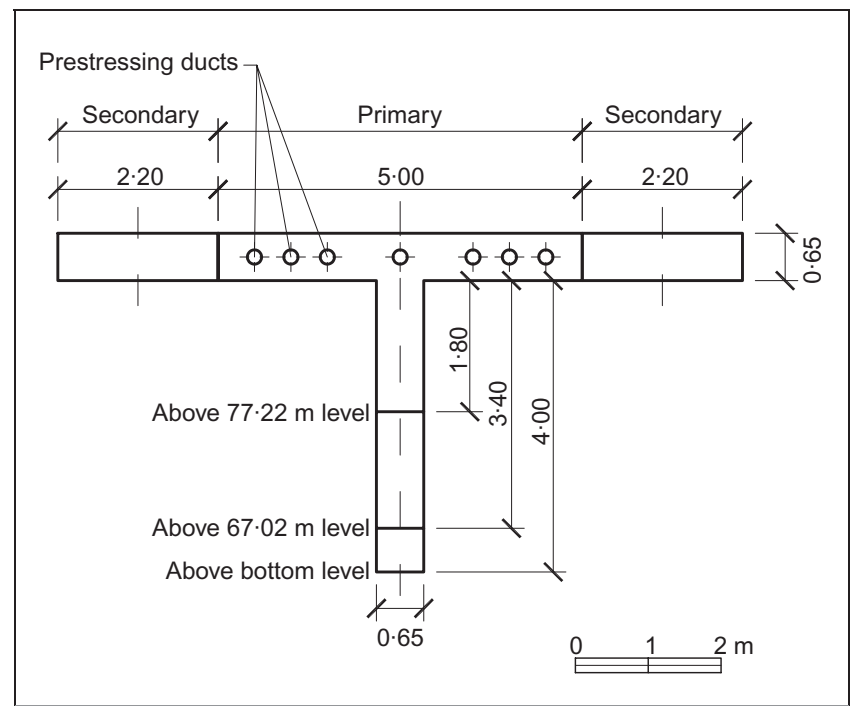

Fig. 5. Cross-section of wall
The most unfavourable conditions were in buttresses B8 and B10. B8 presented the worst soil conditions, whereas B10 was closest to the tunnel.

The verification of the present case has the following aspects to consider:

(a) definition of the earth pressures

(b) verification of the self-stability of the retaining wall

(c) the structural strength of, mainly, the primary panels

(d) accurate prediction of movements that may affect the tunnel.

Earth pressures were computed using a standard limit equilibrium approach with Rankine and Caquot-Kerisel formulations, as described, for instance, by Padfield and Mair. ${ }^{8}$

Structural analyses of the primary panel were performed using finite elements. In the model, earth pressures were applied as distributed loads and the prestressing force as equivalent loads. The prestressing equivalent loads are the vertical load at the top of the wall and its bending moment due to its eccentricity. The interaction between the soil and the structure was modelled by spring elements with a linear model with upper and lower limits. Their stiffness was derived from the subgrade reaction coefficient (Winkler) and the yielding force was obtained from the passive pressure. The flexibility of the foundation was also taken into account by the Winkler coefficient applied to a rectangular equivalent area of $4.65 \mathrm{~m}$ $\times 5.00 \mathrm{~m}$. Table 2 presents the horizontal displacement at the top of the wall obtained by non-linear analysis, varying the embedded length of the wall. The elastic result, considering that the foundation bedrock resists all the pressure, reached $6.5 \mathrm{~mm}$. The final length adopted for the embedded zone was $7 \mathrm{~m}$. For that value the maximum bending moment on the cantilever is $19380 \mathrm{kN} \mathrm{m}$ in service conditions. The compression stresses produced by that moment added to other additional vertical stresses (i.e. due to prestressing) were allowable for the shale bedrock. In addition, no horizontal cracks are expected in the diaphragm wall because the vertical stresses are compressive.

Bonding of the post-tensioned tendons allowed for a significant reduction of the amount of mild steel required to resist the maximum bending moment at ultimate condition. In particular, the total amount of steel section was $6300 \mathrm{~mm}^{2}$ of Y1860S7 prestressing steel $\left(f_{\text {pmax }}=1860 \mathrm{~N} / \mathrm{mm}^{2}\right)$ plus $4400 \mathrm{~mm}^{2}$ of B500S mild steel $\left(f_{\mathrm{yk}}=500 \mathrm{~N} / \mathrm{mm}^{2}\right)$, for each buttressed member. If the prestressing steel had not been 
bonded, providing a long-term prestressing force of $4500 \mathrm{kN}$, the amount of mild steel would have been $14700 \mathrm{~mm}^{2}$.

The tunnel is $7.50 \mathrm{~m}$ wide, and despite its reduced earth cover of 5-7 $\mathrm{m}$ it was excavated underground. The overall state of the tunnel lining was good, with no major cracks in the crown. Compression tests showed an average concrete strength of $13 \mathrm{~N} / \mathrm{mm}^{2}$.

The interaction between the structure and the subway tunnel was analysed in an uncoupled manner. The actual stress state of the tunnel lining was difficult to estimate because of the lack of information about the construction procedure used for the tunnel. In addition, the complexity of the operations to be performed in the site (micropiling, excavations generating 3D effects, etc.) suggested defining a simplified procedure for the interaction analysis. In fact, instead of an accurate prediction of the displacements caused by the work (a very difficult task), a limiting value of the movement that might cause some damage to the tunnel was defined. To estimate that limiting value, a plane-strain finite element model was used involving the geometry of the tunnel and the soil behind the wall.

A set of prescribed displacements was applied to a boundary of the model corresponding to the extrados wall. Usually a linear law with a maximum horizontal movement at the top of the new wall was used. Then the model computed the displacements and stresses generated in the tunnel lining. Most of the analyses assumed linear elastic conditions, which may be considered as conservative in this case. Plastic models for the soil generated, on the whole, fewer movements over the tunnel lining. These analyses also suggested the areas where fissures might appear in the concrete lining and therefore where inspection and monitoring should be concentrated.

These computations were used to estimate a limiting value of $1.5 \mathrm{~cm}$ for the movement of the top of the new wall. The metro administration assumed this value as a warning limit that should be taken into account when monitoring the excavation process.

\section{CONSTRUCTION}

A set of comprehensive drawings explaining the construction procedure is presented in Fig. 6. The construction process began with stabilisation of the existing retaining wall made of masonry, which included micropiling to improve its foundation and thickening of its extrados with $20 \mathrm{~cm}$ of reinforced concrete.

With the existing wall stabilised, hydromill equipment was used to excavate the $\mathrm{T}$ shape of the primary panel. Bentonite mud was employed to prevent collapse of the excavated walls. Then the heavy reinforcement cage-including seven ducts (Fig. 5)-was placed, and all the excavation was filled with concrete as shown in Fig. 6(c). Then the hydromill excavated the secondary panel eroding concrete of the lateral surfaces of the previously built primary panels to improve the connection between them. When the concrete had hardened, five holes were drilled in the bedrock, and the corresponding tendons were installed and prestressed. That is, the stressing of the tendons was carried out before the excavation of the site. Tendons were prestressed in two phases, applying 50\% of the total force-1750 kN per anchor-in each one before commencing excavation. During that excavation process the force in each tendon was checked. At the end of the work a final check was performed just before proceeding with restressing and the injection for bonding the tendons. In longterm conditions, the prestressing force in each tendon should be $900 \mathrm{kN}$ when working as anchors, which means an overall vertical force of $4500 \mathrm{kN}$ every $7 \cdot 20 \mathrm{~m}$.

The excavation was divided into two main stages to allow easy demolition of the unnecessary parts of the upper section of the buttresses. The first stage was $5 \mathrm{~m}$ deep and second was approximately $5.70 \mathrm{~m}$ until the final level of $64.80 \mathrm{~m}$ was reached (Fig. $6(\mathrm{~g})$ ). Noted that the embedded ground between buttresses below level 67.02 was not excavated, in order to allow it to contribute the stability as a berm, as mentioned above in Section 3.

Figure 7 presents a picture of the ducts installed in the T section, and Fig. 8 shows a final stage of the work, when the slab floor between buttresses at level $75.52 \mathrm{~m}$ was being built.

\section{MONITORING}

The behaviour of the retaining structure during construction was controlled by means of surveying the wall itself and the neighbouring tunnel, and by inclinometers installed inside the wall.

The survey in the tunnel was based mainly on convergence measurements in five different sections: four located in the zone affected by the diaphragm wall, and one placed $100 \mathrm{~m}$ away from the wall influence for reference. The measurements, including the last set performed in 2002, showed that vertical convergences were negligible, and horizontal convergences indicated a reduction of less than $2 \mathrm{~mm}$. The same pattern was observed in the reference section. Therefore it was concluded that the effect of the wall on the tunnel was not relevant.

Surveying of the wall consisted of measuring the horizontal and vertical displacements of points located at the top of the wall, for each buttress. In particular, horizontal displacements were used for comparison with the inclinometer measurements. They were considered the main control variable (a maximum of $1.5 \mathrm{~cm}$ adopted according to the analyses described above). Vertical movements were less than $1 \mathrm{~mm}$ after post-tensioning and after excavation.

Four inclinometers were placed at different buttresses. The ducts for the inclinometers were fixed to the reinforcement cage, and no perforation was made to extend their length to the ground. Fig. 9 presents inclinometer readings for buttress B10, the closest to the tunnel. In that figure, profile A was read after finishing the whole diaphragm wall and B was measured just after prestressing, showing a movement towards the tunnel. Profiles C, D and E were measured during the excavation. Measurements F correspond to a date after restressing of the tendons and G 20 days after F. They all show an almost rigid body movement towards the excavation, as was predicted in the design analyses. Prestressing always produced a movement towards the ground. The values of the movements were lower than expected, mainly because of the conservative hypotheses adopted in the design. 


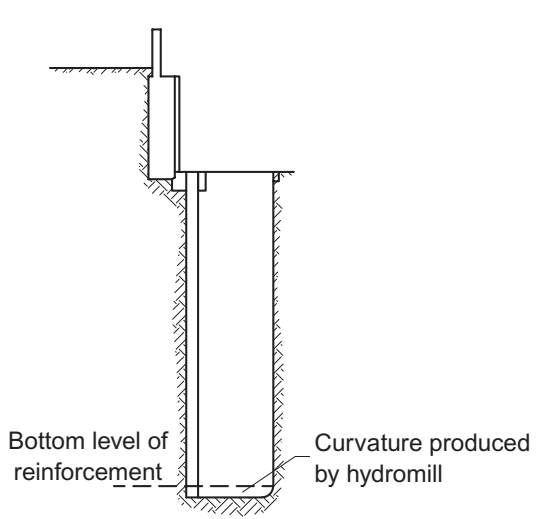

(a)

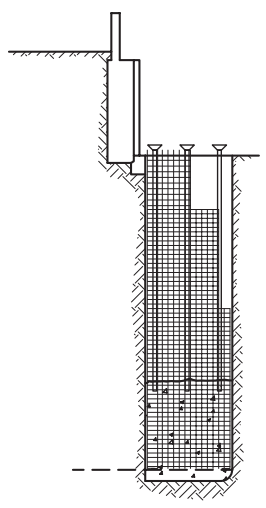

(c)

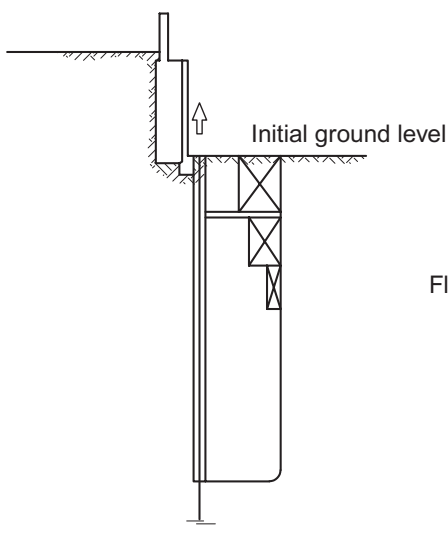

(e)

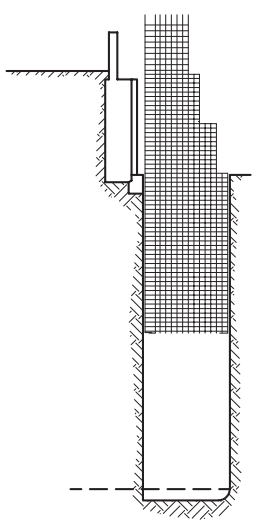

(b)

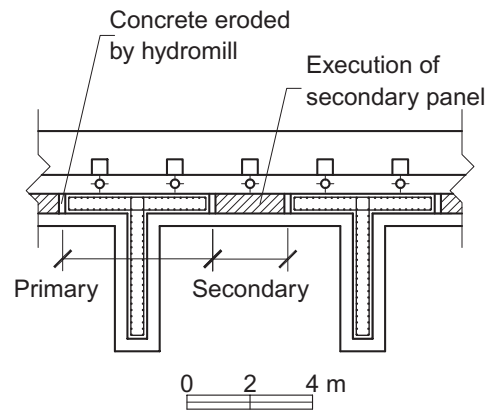

(d)

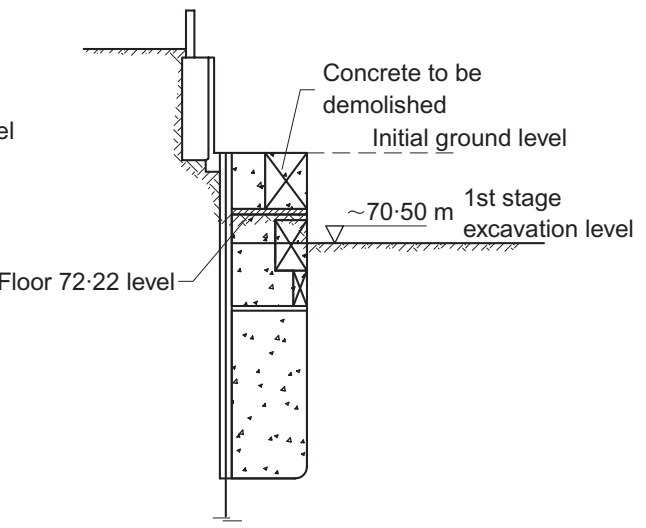

(f)

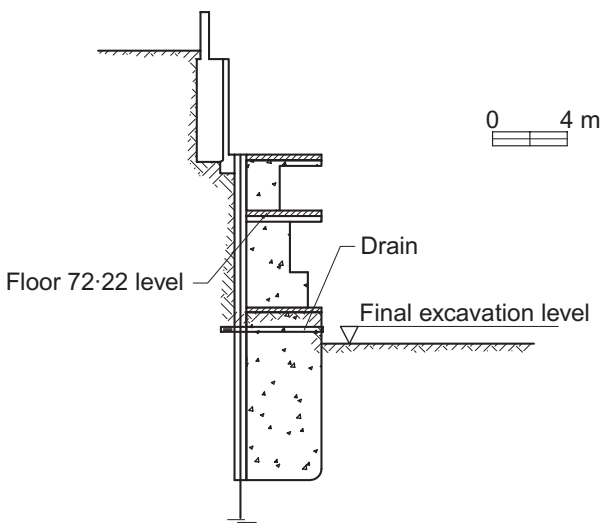

(g) 

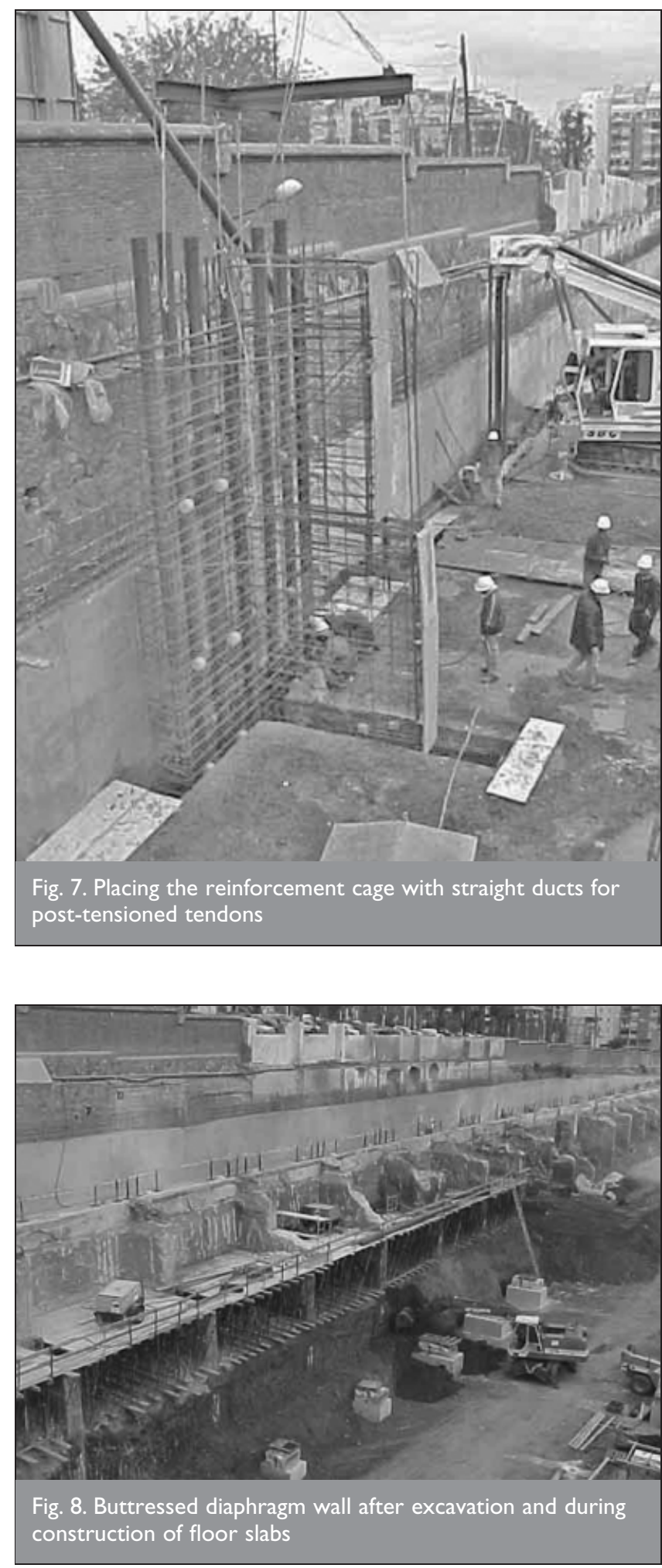

\section{CONCLUSION}

A technical solution for a retaining wall where movements were restricted has been described. The retaining structure had to isolate a building from the vibrations produced by a neighbouring subway tunnel, and the tunnel itself was not to be damaged by the excavation of the site. These two challenges were tackled by designing a self-supporting independent retaining wall, using prestressing and buttresses as the main techniques. The use of prestressing is not usual in this type of foundation, but in this case, where tendons followed a simple straight line, this technique became a competitive solution that could be applied in other circumstances. In addition, the use of

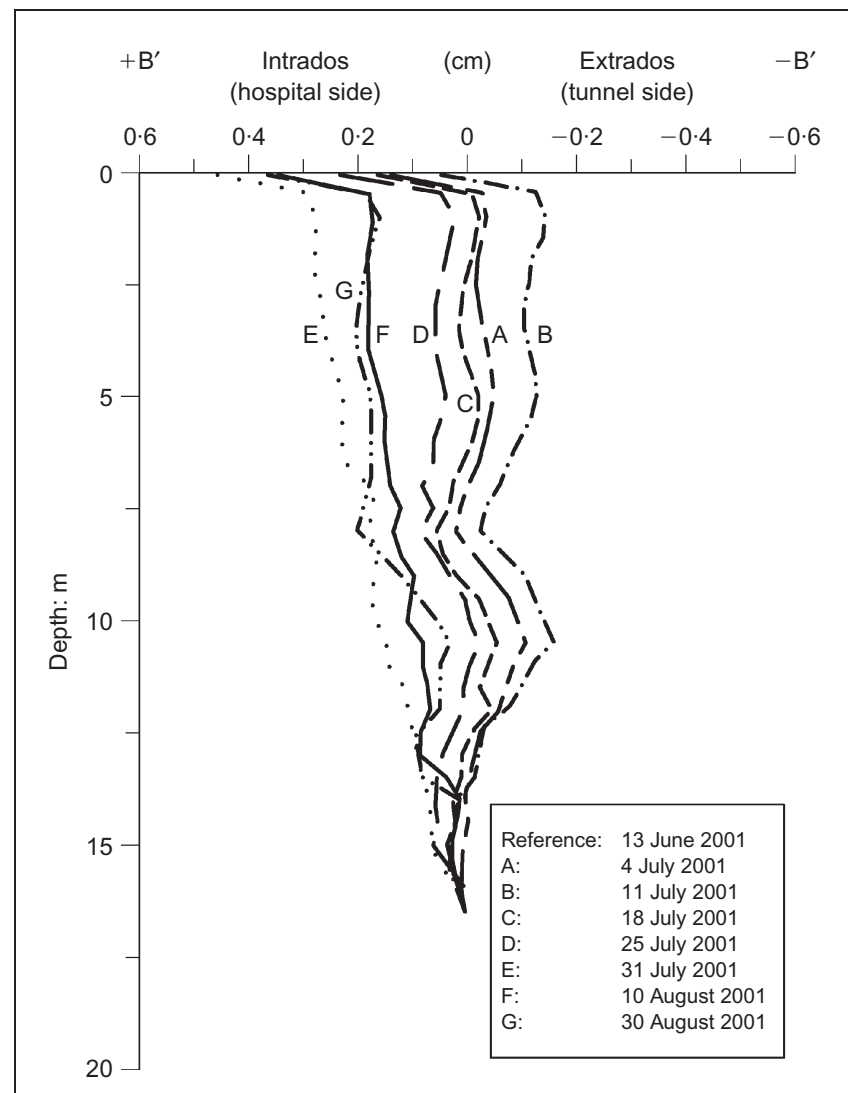

Fig. 9. Inclinometer readings (+B indicates movement towards the excavation)

vertical prestressed anchors significantly reduced the amount of reinforcement and contributed directly to the equilibrium. Finally, monitoring of the wall and the neighbouring tunnel showed that the design and construction process were appropriate for the considered problem.

\section{ACKNOWLEDGEMENTS}

The authors participated in the design phase of the retaining structure, commissioned and funded by the Fundació Privada Hospital de la Santa Creu i Sant Pau, which is gratefully acknowledged. The collaboration of the metro company, Transports Metropolitans de Barcelona, is also acknowledged. The pictures of the construction were generously provided by Mr Carles Jaen from BOMA S.A., general contractor of the structural design of the whole new hospital.

\section{REFERENCES}

1. PULleR M. Deep Excavations: A Practical Manual. Thomas Telford, London, 1996.

2. GYSI H. J., LINDER A. and LEONI R. Prestressed diaphragm walls. In Proceedings of the 6th European Conference on Soil Mechanics and Foundation Engineering, Vienna. Austrian Association of Engineers and Architects, Vienna, 1975, vol. 1, pp. 141-148 (in German).

3. GYSI H. J., LINDER A. and LEONI R. Behaviour of a prestressed diaphragm wall. In Proceedings of the 9th International Conference on Soil Mechanics and Foundation Engineering, Tokyo. Japanese Society for Soil Mechanics and Foundation Engineering, Tokyo, 1977, vol. 2, pp. 83-90.

4. Terzaghi K., Peck R. B. and Mesri G. Soil Mechanics in Engineering Practice. Wiley Interscience, New York, 1996. 
5. Consoli N. C., Schnaid F. and MiLITITSKY J. Interpretation of plate load tests on residual soil site. ASCE Journal of Geotechnical and Geoenvironmental Engineering, 1998, 124, No. 9, 857-867.

6. Simon B. Commentaires sur le choix des coefficients de réaction pour le calcul des écrans de soutènement. Revue Française de Géotechnique, 1995, 71, No. 1, 11-19.

7. LedeSMA A., Molins C. and MARí A. Influencia del nou
Hospital de Sant Pau sobre el túnel del Ferrocarril Metropolità de Barcelona. Final Report (in Catalan), Universitat Politècnica de Catalunya (UPC), Barcelona, 2001.

8. PADFIELD C. J. and MAIR R. J. Design of Retaining Walls Embedded in Stiff Clays. CIRIA Report 104, Construction Industry Research and Information Association, London, 1984.

\section{What do you think?}

To comment on this paper, please email up to 500 words to the editor at journals@ice.org.uk

Proceedings journals rely entirely on contributions sent in by civil engineers and related professionals, academics and students. Papers should be 2000-5000 words long, with adequate illustrations and references. Please visit www.thomastelford.com/journals for author guidelines and further details. 